\title{
Speciation Studies of Copper Complexes with L-Glutamic Acid by Using Diethylaminoethyl Sephadex A-25 Column
}

\author{
Mitsuhiko Taga, Shunitz Tanaka and Masami Fukushima \\ Department of Chemistry, Faculty of Science, Hokkaido University, Sapporo 060, Japan
}

\begin{abstract}
A method to evaluate the complexing ability of copper(II) with L-glutamic acid was studied using a weak-base anion exchanger, diethylaminoethyl Sephadex A-25 (A-25). The species of copper(II) complex with L-glutamic acid were $\mathrm{Cu}(\mathrm{Glu})^{0}(1: 1$ complex $)$ and $\mathrm{Cu}(\mathrm{Glu})_{2}{ }^{2-}(1: 2$ complex $)$. The $1: 2$ complex was retained on $\mathrm{A}-25$ since this complex was anionic. The amount of copper retained on A-25 as a 1:2 complex and that which flowed out as free copper(II) ion and a 1:1 complex were determined by flame atomic absorption spectrometry. From the concentration of the $1: 2$ complex measured, the equations to calculate the stability constants $\left(\beta_{1}\right.$ and $\left.\beta_{2}\right)$ were derived in terms of the equilibria of the solution; the stability constants obtained were in good agreement with values in the literature. The distribution curves of copper species at various $\mathrm{pH}$ were also in good agreement with curves simulated from the estimated stability constants.
\end{abstract}

Keywords Copper, L-glutamic acid, stability constants, diethylaminoethyl Sephadex A-25

Heavy-metal ions in natural water exist in various form: for example, adsorbed on suspended matter and clay minerals, complexed with inorganic and organic matter, and as hydrate ions. ${ }^{1-3}$ Clarifying these chemical forms is very important for biological and enviromental aspects. Studies concerning the speciation of metal ions in natural water have been performed using ion-selective electrodes (ISE) that respond to the activity of free metal ions ${ }^{4,5}$, anodic stripping voltammetry (ASV) that measure free metal ions and labile species $^{6}$, as well as cation exchange methods. ${ }^{7,8}$ However, the ISE method is not sufficiently sensitive to measure trace substances in natural water; the ASV method has a problem that the complex would dissociate in the diffusion layer during electrolysis. ${ }^{9}$

Previously, Hiraide et al. reported that the macroreticular weak-base anion exchanger, diethylaminoethyl Sephadex A-25 (A-25), could be used to measure the species of heavy-metal ions ( $\mathrm{Fe}, \mathrm{Cu}, \mathrm{Cd}, \mathrm{Pb}$ ) binding with humic substances and other anionic ligands in river water. ${ }^{10-12}$ They evaluated the copper-complexing ability of humic substances using an A-25 column. ${ }^{13}$ We also reported on a method to quantitatively evaluate the copper-complexing ability of humic acids in peat soil by A-25. ${ }^{14}$

On the other hand, it was known that there were many other organic ligands than humic substances in natural water: for example, amino acids and fatty acids. ${ }^{1-3}$ These materials were also important in influencing the heavy-metal complexing capacity of natural water as well as humic substances. Especially, Uchiyama et al. reported that the amount of amino acids (free or bound form) correlated with the copper complexing capacity in natural water..$^{15-17}$

In the present work, a method for evaluating the complexing ability of amino acids in natural water was investigated using A-25. L-Glutamic acid was selected as an example of amino acid in natural water, because Lglutamic acid is widely distributed in nature. The species of copper complex with L-glutamic acid were $\mathrm{Cu}(\mathrm{Glu})^{0}$ as a $1: 1$ complex and $\mathrm{Cu}(\mathrm{Glu})_{2}{ }^{2-}$ as a $1: 2$ complex. It seemed that only the 1:2 complex was retained by ion exchange on A-25 since it had an anionic change. The adsorption behavior of copper/Lglutamic acid complex on A-25 was investigated, and the stability constants $\left(\beta_{1}\right.$ and $\left.\beta_{2}\right)$ of their complexes were estimated.

\section{Experimental}

\section{Reagents and materials}

L-Glutamic acid solution was prepared by dissolving L-glutamic acid (Wako Pure Chemical Industries, Ltd.) in a $0.01 \mathrm{M}$ potassium hydroxide solution.

The standard copper solution $(1 \mathrm{~g} / 1)$ was prepared by dissolving electric copper (Mitsuwa Pure Chemicals, purity $99.999 \%$ ) in concentrated nitric acid and diluting to a $0.01 \mathrm{M}$ nitric acid solution.

The diethylaminoethyl Sephadex A-25 (Pharmacia LKB Biochemistry, $\mathrm{Cl}^{-}$form) was washed by ultrasonic irradiation for $20 \mathrm{~min}$ in a $0.1 \mathrm{M}$ hydrochloric acid solution and then washed with water. It was next swollen in a $0.05 \mathrm{M}$ potassium chloride solution with an adjusted $\mathrm{pH}$ of $6-7$ by a potassium hydroxide solution. Two milliliters of A-25 were packed into a column 
which was washed with $50 \mathrm{ml}$ of water and passed through a $20 \mathrm{ml}$ of a buffer solution at the experimental pH.

The other reagents were of analytical reagent grade (Wako Pure Chemical Industries, Ltd.).

\section{Apparatus and instruments}

A polypropylene column of $40 \mathrm{~mm} \times 8 \mathrm{~mm}$ i.d. (BioRad) was used. The copper concentration was measured by a HITACHI 170-50 atomic absorption spectrometer (AAS) with the PTFE funnel to the nebulizer needle. The absorbance of the copper was measured at $324.7 \mathrm{~nm}$ in the air/acetylene flame. A HORIBA M8L-type $\mathrm{pH}$ meter was used for the $\mathrm{pH}$ measurement.

\section{Procedure}

After the $\mathrm{pH}$ of a sample solution containing copper(II) and L-glutamic acid was adjusted, $15 \mathrm{ml}$ of the sample solution was passed through the column at a flow rate of $5 \mathrm{ml} / \mathrm{min}$. The A-25 column was then washed with water. The A-25 in the column was transferred to a centrifuge tube and $8 \mathrm{ml}$ of $4 \mathrm{M}$ nitric acid solution was added. The copper adsorbing on A25 was desorbed by ultrasonic irradiation for $5 \mathrm{~min}$. The solution and A-25 was separated by centrifugation for $3 \mathrm{~min}$ and the supernatant was transferred to a $50 \mathrm{ml}$ beaker. Eight milliliters of $4 \mathrm{M}$ nitric acid solution were again added to the centrifuge tube; the same procedure was then repeated. The supernatant introduced into a $50 \mathrm{ml}$ beaker was dried up on a hot plate. The residue was decomposed by adding $0.5 \mathrm{ml}$ of concentrated nitric acid and diluting to $10 \mathrm{ml}$. One hundred microliters of the aliquot was introduced into a PTFE funnel of AAS. The concentration of the 1:2 complex could be calculated by dividing the amount of copper on A-25 by the volume of the original sample solution. The effluent containing free copper and a 1:1 complex was enriched by heating on a hot plate and then diluted to $10 \mathrm{ml}$ with a $0.2 \mathrm{M}$ nitric acid solution. One hundred microliters of the aliquot was introduced into AAS.

\section{Results and Discussion}

Adsorption behavior of copper/L-glutamic acid on A-25 column

L-Glutamic acid forms a $1: 1$ or $1: 2$ complex with copper(II). At $\mathrm{pH}=6$, the $1: 2$ complex would be mainly an anionic species. When the acetate buffer solution at pH 5.5 or 6 containing copper(II) ion was passed through the A-25 column, the copper was not retained on A-25 at all. But when L-glutamic acid was added into this solution, copper was retained on the A25 column. It therefore was seemed that a $1: 2$ complex of copper/L-glutamate could be retained on A-25 by ion-exchange, but the cationic or neutral species (for example, free copper ion and a 1:1 complex) could not be retained and flowed out under these conditions.

\section{Effect of the flow rate of sample solution}

In the case of studying the complexing equilibrium in a solution by ion-exchange methods, it is important that the complexing equilibrium in the solution does not change during ion-exchange. Therefore, the effect of the flow rate of the sample solution on the amount of copper retained on A-25 was investigated. At various ratios of the concentration of copper to $\mathrm{L}-$ glutamic acid, the amount of copper retained on A-25 was constant at flow rates within the range 1 to $20 \mathrm{ml} / \mathrm{min}$. It therefore, appeared that the amount of copper retained on A-25 would be influenced by the ratio of the concentration of copper to L-glutamic acid in the solution irrespective of the flow rate. That is, these results obtained by an A-25 column method would reflect the complexing equilibria in the solution and the equilibria would not change during ion-exchange.

\section{Estimation of the stability constants of copper(II)/L- ghtamic acid}

In order to estimate the copper complexing ability of L-glutamic acid by measuring the copper retained on A-25 as a 1:2 complex, the complexing equilibrium in the solution is treated as illustrated below. The complex formation of copper(II) (M) with L-glutamic acid $(\mathrm{L})$ is written as

$$
\mathrm{M}+\mathrm{L} \rightleftharpoons \mathrm{ML}
$$

and

$$
\mathrm{ML}+\mathrm{L} \rightleftharpoons \mathrm{ML}_{2}
$$

At this time, the stability constants $\left(\beta_{1}\right.$ and $\left.\beta_{2}\right)$ are written as

$$
\beta_{1}=[\mathrm{ML}] /([\mathrm{M}][\mathrm{L}])
$$

and

$$
\beta_{2}=\left[\mathbf{M L}_{2}\right] /\left([\mathbf{M}][\mathbf{L}]^{2}\right)
$$

From the mass balance of the solution,

$$
\left[\mathbf{M}_{t}\right]=[\mathrm{M}]+[\mathrm{ML}]+\left[\mathrm{ML}_{2}\right]
$$

where $\left[\mathrm{M}_{1}\right]$ is the total copper concentration of the original solution. L-Glutamic acid is in association equilibria with protons in the solution. The total concentration of $\mathrm{L}$-glutamic acid in the original solution $\left(c_{\mathrm{L}}\right)$ can be written as

$$
c_{\mathrm{L}}=[\mathrm{L}]+[\mathrm{ML}]+2\left[\mathrm{ML}_{2}\right]+[\mathrm{HL}]+\left[\mathrm{H}_{2} \mathrm{~L}\right]+\left[\mathrm{H}_{3} \mathrm{~L}\right] .
$$

The side reaction coefficient for protonation of Lglutamic acid, $\alpha_{\mathrm{L}(\mathrm{H})}$, is written as 


$$
\begin{aligned}
\alpha_{\mathrm{L}(\mathrm{H})} & =\left([\mathrm{L}]+[\mathrm{HL}]+\left[\mathrm{H}_{2} \mathrm{~L}\right]+\left[\mathrm{H}_{3} \mathrm{~L}\right]\right) /[\mathrm{L}] \\
& =1+K_{\mathrm{HL}}[\mathrm{H}]+K_{\mathrm{HL}} K_{\mathrm{H} 2 L}[\mathrm{H}]^{2}+K_{\mathrm{HL}} K_{\mathrm{H} 2 \mathrm{~L}} K_{\mathrm{H} 3 \mathrm{~L}}[\mathrm{H}]^{3},(7)
\end{aligned}
$$

where $K_{\mathrm{HL}}, K_{\mathrm{H} 2 \mathrm{~L}}$ and $K_{\mathrm{H3L}}$ are consecutive stability constants of L-glutamic acid with a proton. From the stability constants reported by Kortüm et al. ${ }^{18}$, and the concentration of protons measured by the glass electrode, $\alpha_{L(H)}$ could be calculated.

Moreover, Eq. (6) can be divided by [L]; from Eq. (7),

$$
c_{\mathrm{L}} /[\mathrm{L}]=\left([\mathrm{ML}]+2\left[\mathrm{ML}_{2}\right]\right) /[\mathrm{L}]+\alpha_{\mathrm{L}(\mathrm{H})} .
$$

From a rearrangement of Eq. (8),

$$
[\mathrm{L}]=\left(c_{\mathrm{L}}-\left([\mathrm{ML}]+2\left[\mathrm{ML}_{2}\right]\right)\right) / \alpha_{\mathrm{L}(\mathrm{H})} \text {. }
$$

Equation (5) is divided by [M] and rearranged using Eqs. (3) and (4),

$$
\begin{aligned}
{\left[\mathrm{M}_{\mathrm{t}}\right] /[\mathrm{M}] } & =1+[\mathrm{ML}] /[\mathrm{M}]+\left[\mathrm{ML}_{2}\right] /[\mathrm{M}] \\
& =1+\beta_{1}[\mathrm{~L}]+\beta_{2}[\mathrm{~L}]^{2} .
\end{aligned}
$$

Further from a rearrangement of Eq. (10)

$$
\left(\left[\mathrm{M}_{\mathrm{t}}\right] /[\mathrm{M}]-1\right) /[\mathrm{L}]=\beta_{1}+\beta_{2}[\mathrm{~L}] \text {. }
$$

Equation (9) is put into Eq. (11),

$$
\begin{aligned}
\left(\left[\mathrm{M}_{\mathrm{t}}\right] /[\mathrm{M}]-1\right) \alpha_{\mathrm{LH})} /\left(c_{\mathrm{L}}-\left([\mathrm{ML}]+2\left[\mathrm{ML}_{2}\right]\right)\right) \\
\quad=\beta_{1}+\beta_{2}\left(c_{\mathrm{L}}-\left([\mathrm{ML}]+2\left[\mathrm{ML}_{2}\right]\right)\right) / \alpha_{\mathrm{L}(\mathrm{H})} .
\end{aligned}
$$

When the $c_{\mathrm{L}}$ value was larger than $\left[\mathrm{M}_{\mathrm{t}}\right]$, the following equation could be assumed:

$$
\left[\mathrm{ML}_{2}\right] \gg[\mathrm{ML}] \text {. }
$$

The validity of this assumption is discussed later. From Eq. (12) and Eq. (13) can be simplified as

$$
\begin{aligned}
\left(\left[\mathrm{M}_{\mathrm{t}}\right] /[\mathrm{M}]-1\right) \alpha_{\mathrm{LH}}^{2} /\left(c_{\mathrm{L}}-2\left[\mathrm{ML}_{2}\right]\right) \\
=\alpha_{\mathrm{L}(\mathrm{H})} \beta_{1}+\beta_{2}\left(c_{\mathrm{L}}-2\left[\mathrm{ML}_{2}\right]\right)
\end{aligned}
$$

Equation (14) shows that there was a linear relationship between $c_{L}-2\left[\mathrm{ML}_{2}\right]$ and $\left(\left[\mathrm{M}_{\mathrm{t}}\right] /[\mathrm{M}]-1\right) /\left(c_{\mathrm{L}}-2\left[\mathrm{M}_{\mathrm{t}}\right]\right)$, and that the $\beta_{1}$ and $\beta_{2}$ values could be estimated by the intercept and the slope of this line, respectively. $\left[\mathrm{ML}_{2}\right]$ could be obtained by measuring the copper on A-25 by AAS, and the [M] and $c_{2}-2\left[\mathrm{ML}_{2}\right]$ values could be calculated from Eqs. (5) and (6). Under the conditions that $c_{\mathrm{L}}=50 \mu \mathrm{M}$ and $\mathrm{pH}=6$, a $c_{\mathrm{L}}-2\left[\mathrm{ML}_{2}\right]$ vs. $\left(\left[\mathrm{M}_{\mathrm{t}}\right] /\right.$ $[\mathrm{M}]-1) /\left(c_{\mathrm{L}}-2\left[\mathrm{ML}_{2}\right]\right)$ plot was drawn (Fig. 1). The stability constants estimated by the intercept and the slope of this line were as follows: $\log \beta_{1}=6.0 \pm 0.3, \log$ $\beta_{2}=15.2 \pm 0.1 \quad(n=3)$. The value of $\log \beta_{2}$ was in good agreement with the value reported by Norman et al. ${ }^{19}$

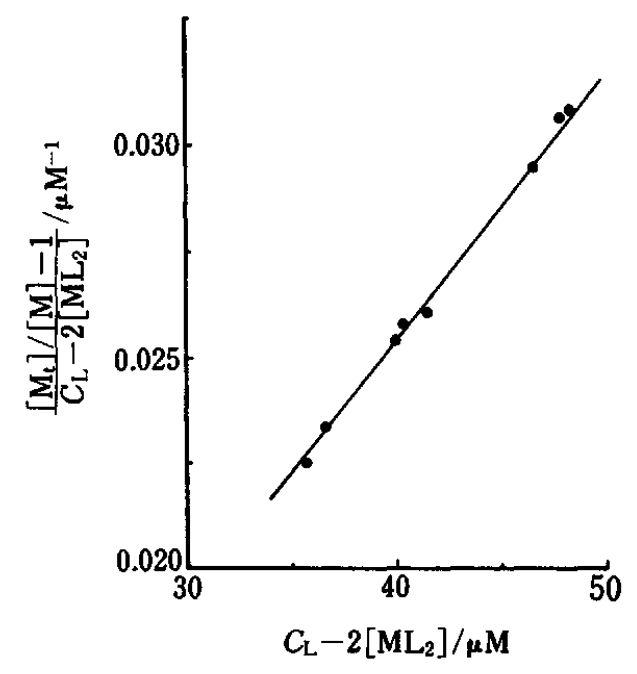

Fig. 1 Calculation of stability constants. $\left[\mathrm{M}_{\mathrm{t}}\right]=0-15.9 \mu \mathrm{M}$, $c_{\mathrm{L}}=50 \mu \mathrm{M}, \mathrm{pH}=6$.

By using the $\beta_{1}$ and $\beta_{2}$ values obtained, the concentration of copper species [M], [ML] and $\left[\mathrm{ML}_{2}\right]$ were simulated by computer; these values were then compared with the experimental values. The conditional stability constants $\left(\boldsymbol{\beta}_{1}^{\prime}\right.$ and $\left.\boldsymbol{\beta}_{2}^{\prime}\right)$ are written as

$$
\beta_{1}^{\prime}=\beta_{1} / \alpha_{L(\mathrm{H})}
$$

and

$$
\beta_{2}^{\prime}=\beta_{2} / \alpha_{L(H)} \text {. }
$$

The concentration of copper species $[M],[M L]$ and $\left[\mathrm{ML}_{2}\right]$ could be calculated according to

$$
\begin{aligned}
& {[\mathrm{M}]=\left[\mathrm{M}_{1}\right] /\left(1+\beta_{1}[\mathrm{~L}]+\beta_{2}[\mathrm{~L}]^{2}\right)} \\
& {[\mathrm{ML}]=\left[\mathrm{M}_{1}\right] \beta_{1}[\mathrm{~L}] /\left(1+\beta_{1}[\mathrm{~L}]+\beta_{2}[\mathrm{~L}]^{2}\right)}
\end{aligned}
$$

and

$$
\left[\mathrm{ML}_{2}\right]=\left[\mathrm{M}_{\mathrm{t}}\right] \beta_{2}[\mathrm{~L}]^{2} /\left(1+\beta_{1}[\mathrm{~L}]+\beta_{2}[\mathrm{~L}]^{2}\right) \text {. }
$$

The $\beta_{1}^{\prime}$ and $\beta_{2}^{\prime}$ values could be calculated from the $\alpha_{L(H)}$ value of L-glutamic acid at $\mathrm{pH}=6$. The simulation curve of $\left[\mathrm{ML}_{2}\right]$ vs. $\left[\mathrm{M}_{1}\right]$ is given in Fig. 2. This curve is in good agreement with the experimentally measured $\left[\mathrm{ML}_{2}\right]$. Moreover, the simulation curves of $\left[\mathrm{M}_{\mathrm{t}}\right] \boldsymbol{v s}$. $[\mathrm{M}]$ and $\left[\mathrm{M}_{t}\right]$ vs. [ML] are also given in Fig. 2. Since [ML] was less than $3 \%$ of $\left[\mathrm{ML}_{2}\right]$ over the range 0 to $16 \mu \mathrm{M}\left[\mathrm{M}_{t}\right]$, it was confirmed that the assumption $[\mathrm{ML}] \ll\left[\mathrm{ML}_{2}\right]$ at Eq. (13) was appropriate.

\section{Stability constants of various $c_{L}$}

If the $c_{\mathrm{L}}$ values were known, stability constants $\beta_{1}$ and $\beta_{2}$ could be estimated by only measuring $\left[\mathrm{ML}_{2}\right]$ at a certain $\left[\mathrm{M}_{t}\right]$ and $\mathrm{pH}$. Equation (9) was substituted in Eq. (4) and from an approximation of Eq. (13),

$$
\beta_{2}=\alpha_{(H)}^{2}\left[\mathrm{ML}_{2}\right] /\left([\mathrm{M}]\left(c_{\mathrm{L}}-2\left[\mathrm{ML}_{2}\right]\right)\right)^{2} .
$$




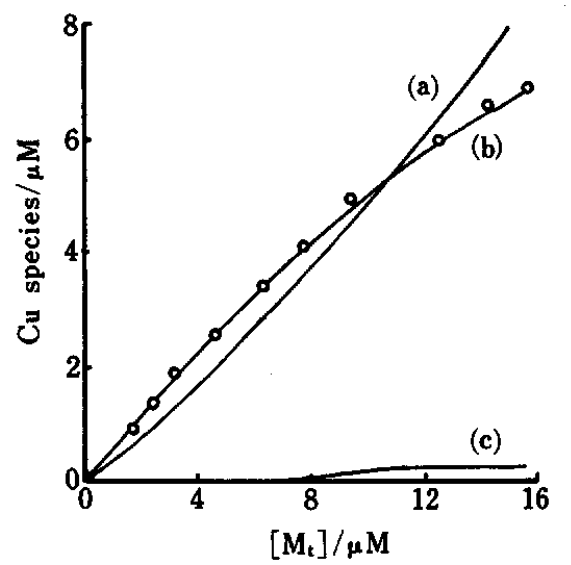

Fig. 2 Concentration of the copper species with L-glutamic acid (L). The simulation curves: (a), [M]; (b), [ML $]$; (c), [ML]. O, [ $\left.\mathrm{ML}_{2}\right]$ measured. $\left[\mathrm{M}_{\mathrm{t}}\right]=0-15.9 \mu \mathrm{M}, c_{\mathrm{L}}=50 \mu \mathrm{M}$, pH=6.0.

Table 1 Stability constants of copper/L-glutamic acid complexes for various $c_{\mathrm{L}}$

\begin{tabular}{cccccc}
\hline$c_{\mathrm{L}} / \mu \mathrm{M}$ & 35 & 40 & 50 & 75 & 100 \\
\hline $\log \beta_{1}$ & 5.8 & 6.0 & 6.2 & 5.8 & 6.1 \\
$\log \beta_{2}$ & 15 & 15 & 15 & 15 & 15 \\
\hline
\end{tabular}

$\left[\mathrm{M}_{\mathrm{t}}\right]=15.9 \mu \mathrm{M}, \mathrm{pH}=6$.

From the simultaneous equation between Eq. (14) and (17), the $\beta_{1}$ and $\beta_{2}$ values could be estimated. They are shown in Table 1. The values of $\beta_{1}$ and $\beta_{2}$ were in good agreement with the values estimated by the plot in Fig. 1.

\section{Copper(II) species in sample solutions at various $p H$}

The concentrations of the copper species in a solution containing L-glutamic acid at various $\mathrm{pH}$ were calculated using the $\beta_{1}$ and $\beta_{2}$ values; the distribution curves are given in Fig. 3. [ML2] and the copper concentration in experimentally measured effluent are also given in Fig. 3 (O or in Fig. 3) and are in good agreement with the calculated distribution curves. Under the condition of more excess ligand concentration than $\left[\mathrm{M}_{\mathrm{t}}\right],[\mathrm{ML}]$ hardly formed and copper was present almost completely as $\left[\mathrm{ML}_{2}\right]$. It thus seemed that assuming Eq. (13) was appropriate. From these results it was confirmed that the only $1: 2$ complex, $\left[\mathrm{ML}_{2}\right]$, was quantitatively retained on the A-25 column. It was therefore suggested that the A-25 column could be used to quantitatively evaluate the copper complexing ability of an organic ligand, such as an amino acid in natural water.

\section{References}

1. S. Faust and J. V. Hunter, "Organic Compounds in Aqueous Environment", pp. 239 -313, Marcel Dekker,

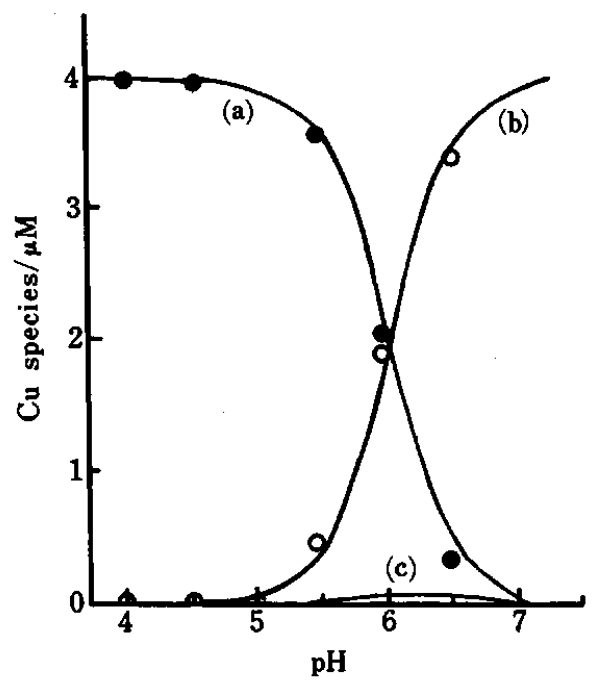

Fig. 3 Distribution curves of copper species at various $\mathrm{pH}$. The simulation curves: (a), [M]; (b), [ML $\mathrm{ML}_{2}$; (c), [ML]. O, copper on A-25;, copper in effluent, measurement values. $\left[\mathrm{M}_{\mathrm{l}}\right]=4.0 \mu \mathrm{M}, c_{\mathrm{L}}=50 \mu \mathrm{M}$.

New York, 1971.

2. T. M. Florence and G. E. Batley, CRC Crit. Rev. Anal. Chem., 9, 219 (1980).

3. T. M. Florence, Talanta, 29, 345 (1982).

4. J. Buffle, F.-L. Greter and W. Haerdi, Anal. Chem., 49, $216(1977)$

5. W. T. Bresnahan, C. L. Grant and J. H. Weber, Anal. Chem., 50, 1675 (1978).

6. M. Sugawara, P. Valenta, H. W. Nurnberg and T. Kambara, J. Electroanal. Chem. Interfacial Electrochem., 180, 343 (1984).

7. R. J. Stolzberg and D. Rosin, Anal. Chem., 49, 226 (1977).

8. P. Figura and B. McDuffie, Anal. Chem., 49, 1950 (1977).

9. G. A. Bhat, J. H. Weber, J. R. Tuschall and P. L. Brezonik, Anal. Chem., 54, 2116 (1982).

10. M. Hiraide, S. Tillekeratne, K. Otsuka and A. Mizuike, Anal. Chim. Acta, 172, 215 (1985).

11. S. Tillekeratne, T. Miwa and A. Mizuike, Mikrochim. Acta [Wien], 1985 III, 289.

12. M. Hiraide, M. Ishii and A. Mizuike, Anal. Sci., 4, 605 (1988).

13. M. Hiraide, F.-L. Ren, R. Tamura and A. Mizuike, Mikrochim. Acta [Wien], 1987 II, 137.

14. M. Taga, S. Tanaka and M. Fukushima, Anal. Sci., 5, 597 (1989).

15. M. Uchiyama, Y. Nakajima and H. Akaiwa, Nippon Kagaku Kaishi, 1988, 2026.

16. M. Uchiyama, H. Kawamoto, H. Kawai and H. Akaiwa, Nippon Kagaku Kaishi, 1989, 1135.

17. M. Uchiyama, H. Kawamoto, H. Kawai and H. Akaiwa, Nippon Kagaku Kaishi, 1989, 1140.

18. G. Kortüm, W. Vogel and K. Andrussow, Pure Appl. Chem., 1, 332 (1961).

19. C. Norman and E. Doody, J. Am. Chem. Soc., 74, 4184 (1952). 